\title{
Analysis of the Efficiency of Using Heat Exchangers with Porous Inserts in Heat and Gas Supply Systems
}

\author{
Natalia Rydalina 1,*, Elena Antonova ${ }^{1}$, Irina Akhmetova ${ }^{2}$, Svetlana Ilyashenko ${ }^{3}$, \\ Olga Afanaseva ${ }^{4}\left(\mathbb{D}\right.$, Vincenzo Bianco ${ }^{5}(\mathbb{D})$ and Alexander Fedyukhin ${ }^{6}$ \\ 1 Department of Industrial Heat Power Engineering, Industrial University of Tyumen, 625000 Tyumen, Russia; \\ antonovaeo@tyuiu.ru \\ 2 Department of Economics and Organization of Production, Kazan State Power Engineering University, \\ Kazan, 420066 Tatarstan, Russia; irina_akhmetova@mail.ru \\ 3 Department of Trade Policy, Plekhanov Russian University of Economics, 117997 Moscow, Russia; \\ Ilyashenko.sb@rea.ru \\ 4 Higher School of Nuclear and Heat Power Engineering, Peter the Great St. Petersburg Polytechnic \\ University, 195251 St. Petersburg, Russia; eccolga@mail.ru \\ 5 DIME/TEC, University of Genoa, 16145 Genoa, Italy; vincenzo.bianco@unige.it \\ 6 Energy Eficiency and Hydrogen Technology Department, Power Engineering Institute, National Research \\ University Moscow, 111250 Moscow, Russia; Fedyukhinav@yandex.ru \\ * Correspondence: rydalinanv@tyuiu.ru; Tel.: +7-922-261-65-41
}

Received: 28 October 2020; Accepted: 6 November 2020; Published: 10 November 2020

\begin{abstract}
The creation of efficient and compact heat exchangers is one of the priority tasks arising during the design of heat and gas supply to industrial and residential buildings. As a rule, finned surfaces and turbulization of heat carrier flows are used to increase the efficiency of heat exchange in heat exchangers. The present paper proposes to use novel materials, namely porous material, in the design of highly efficient heat exchangers. The investigation was carried out experimentally and theoretically. To study the possibility of creating such heat exchangers, a multi-purpose test bench is created. The aim of the study was to assess the intensity of heat transfer in heat exchangers using porous metal. Laboratory tests are carried out as part of the experimental study. In the theoretical study, the classical equation for the change in the heat flux density when the coolant passes through the porous insert was used. As a result, a mathematical model was obtained in the form of a second-order differential equation. Boundary conditions were set and a particular solution was obtained. The results of theoretical calculations were compared with experimental data. The performed study experimentally confirmed the efficiency of using porous metal inserts in the design of shell-and-tube heat exchangers. The compiled mathematical model allows one to perform engineering calculations of the considered heat exchangers with porous inserts.
\end{abstract}

Keywords: heat exchangers; porous metals; multi-purpose test bench; freon; differential equation; cooling intensity

\section{Introduction}

Heat exchangers (HE) are one of the main units of heat and gas supply systems in industrial and residential buildings, therefore, the issue of improving their efficiency is relevant. The main direction of improving the efficiency of HE equipment is to increase the intensity of heat exchange; most often this is achieved by the use of finned surfaces and turbulization of heat carrier flows [1,2].

To turbulize coolant flows, one uses turbulizing grids, creates artificial roughness, and causes pulsations. It is advisable to use such methods for low Reynolds numbers when coolant flows in a transient mode. When using such methods, there appears a moment when further turbulization of 
flow is economically inexpedient, since, with an increase in the Reynolds criterion, a gradual decrease in growth of heat transfer coefficient occurs.

The use of finned heat exchange surfaces is efficient both for increasing heat transfer and for reducing the metal consumption of heat exchange equipment [3]. The finned heat exchange surface significantly exceeds the surface of the supporting pipes, and it is not subject to pressure from one side, therefore, the ribs can be thinner than the walls of the supporting pipes. All this makes it possible to significantly reduce the consumption of metal required for producing heat exchange equipment. However, it is difficult to obtain a significant increase in the heat transfer coefficient.

One of the promising ways to increase the intensity of heat transfer is the use of various designs of heat exchangers [4-6] and modern materials in them [7-9], for example, porous metals [10,11].

The choice of porous metals for the designs of heat exchangers depends on their application [12,13]. For example, porous metals are used in cooling systems for rocket engines, as well as in the chemical and petrochemical industries [14-16]. Some devices use porous metals as turbulators of heat carrier flows. In this case, the porous material is used as a coating for heat transfer surfaces [17,18]. There are also constructions in which the interchannel spaces for coolant flow are filled with porous metal, which serves as a means for intensifying heat transfer [8]. In addition, three-layer porous evaporating surfaces have been created, in which porous cermet materials of different porosity are used simultaneously [19].

There are some types of plate heat exchangers in which the inter-plate channels for coolant motion are filled with porous metal inserts. These inserts have a large specific area of the inner surface of the frame and small equivalent diameters of the inner channels, providing a high intensity of heat exchange of working media. Such design significantly increases heat transfer [20,21].

Porous-compact heat exchangers are also used, the operation principle of which is based on intensification of heat transfer processes by introducing a porous filler made of materials with high thermal conductivity into the channels. One of the most efficient designs of such heat exchangers uses for filling a highly porous material with a variable relative thickness of the porous material. The body has a cylindrical, round, or oval cross-section [22,23].

Heat carriers in such heat exchangers can be different: "liquid-gas" and "gas-gas" [24]. In heat exchangers of the "liquid-gas" type, a two-phase heat carrier can also be used. The designs of such heat exchangers can also contain porous metals for the flow of one of the coolants [25]. Such devices are most often used to stabilize the temperature of one of the coolants.

Thus, the problem of increasing the intensity of heat transfer using porous metals is urgent. The use of standard methods for heat exchangers calculation in this case is not possible due to the absence of standard approaches for determining the area of the inner surface with pores. The research is unique and novel since a mathematical model of the considered heat exchanger has been obtained, which can be used in engineering calculations.

The purpose of this study is to assess the intensity of heat transfer in heat exchangers with porous metal of different porosity.

To achieve this purpose, it is necessary to consistently solve the following tasks:

(a) To carry out a number of experiments and process the obtained data in order to confirm the assumption of an increase in the intensity of heat transfer when using porous metals in the design of heat exchangers;

(b) To construct a mathematical model that makes it possible to carry out calculations of heat exchangers with porous metals;

(c) To experimentally confirm the correctness of the compiled model and to analyze the obtained results.

\section{Materials and Methods}

To solve the set tasks, laboratory experiments were initially carried out, confirming the fact of an increase in heat transfer when using porous metals in heat exchangers. A multi-purpose test bench was developed and created at the Department of Industrial Heat Power Engineering of the Tyumen 
Industrial University. The test bench allows one to assess and study metals of various porosities in the design of shell-and-tube heat exchangers in order to increase the intensity of heat transfer [26,27]. The schematic diagram of the experimental test bench is shown in Figure 1.

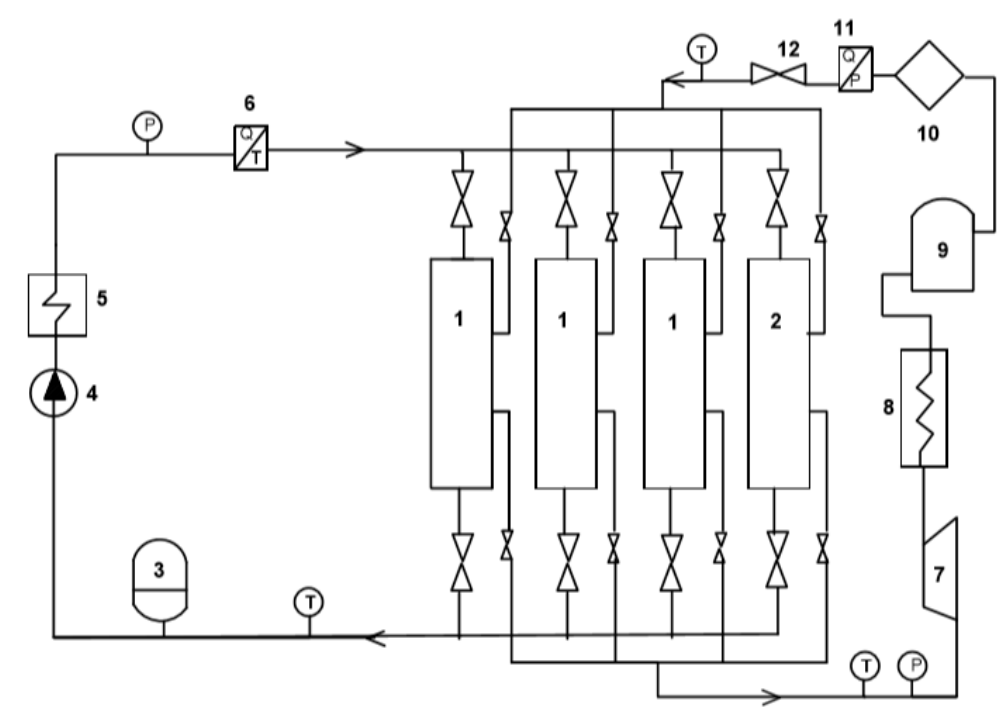

Figure 1. Experimental test bench: 1, heat exchangers with porous metals; 2 , heat exchanger without porous metals; 3, expansion tank; 4, pump; 5 , hot water boiler; 6 , control and measuring device; 7, compressor; 8, condenser; 9 , receiver; 10 , filter moisture separator; 11 , control and measuring device; 12 , throttle; $\mathrm{P}$ is pressure; $\mathrm{T}$ is temperature; $\mathrm{G}$ is coolant flow rate.

Three heat exchangers with porous inserts and one heat exchanger without porous materials were fixed on the test bench. The heat exchangers were counterflow: water flows through the central copper pipes, and freon moves in the opposite direction through the pores of inserts. The motion of water is carried out by a pump. The water temperature can be changed since the boiler (5) is installed after the pump (4). A refrigeration circuit was created for freon motion. Thus, the unit included two circuits: one for water circulation, the other for freon circulation. The first circuit with water was equipped with pump (4), boiler (5) for heating water, and control and measuring device (6), which makes it possible to track the change in water temperature over time and monitor the mass flow rate. The freon circuit is created using the principle of a refrigeration unit and is equipped with compressor (7), condenser (8), receiver (9), a moisture-separating filter, (10) and a throttle (12). In addition, the freon circuit (Figure 1) was equipped with devices for measuring temperature and freon pressure at the inlet and outlet to the compressor and flow meter (11). The unit operates on R404a freon, as it is one of the safest fluids for this kind of work.

The test bench was equipped with valves and gates both at water and freon circuits. The presence of valves allows one to include in the circuit four heat exchangers with various properties and separately control the characteristics of each of the resulting circuits. These valves allow not only changing the working areas, but also regulating the flow rate of coolants. The control and measuring devices record changes in flow and temperature. The pump, which is installed in the water supply system, ensures the operation of the system in two modes of water rates according to the pump's technical passport. The first mode allows one to work with a productivity of up to $22 \mathrm{l} / \mathrm{min}$, and the second mode can reach productivity up to $48 \mathrm{l} / \mathrm{min}$.

In this work, four types of heat exchangers were investigated. Three of them were with various porosities, and the fourth one was without inserts. The porosity of the inserts $p$ was taken as the ratio of the pore volume to the entire volume of material. Three heat exchangers were made using aluminum with porosities of $p=0.49, p=0.62$, and $p=0.47$ (located one after another and denoted as 1 in Figure 1). The porous parts of heat exchangers were cylinders made of porous aluminum with 
a diameter of $49 \mathrm{~mm}$ and a height of $50 \mathrm{~mm}$. To insert the pipes through which the coolant flows, each cylinder had 19 holes of $6 \mathrm{~mm}$ each (Figure 2). There was no porous filling in the fourth heat exchanger. Aluminum was chosen as a material with high thermal conductivity. The most widely used metals with high thermal conductivity are copper, aluminum, and brass. Copper has a higher thermal conductivity $(400 \mathrm{~W} / \mathrm{m} \cdot \mathrm{K})$, but it is a "heavy" metal, less ductile (so to speak) than aluminum, and 3-4 times more expensive than aluminum in cost. Brass, as compared with aluminum, has a lower thermal conductivity $(100 \mathrm{~W} / \mathrm{m} \cdot \mathrm{K})$, and in addition, it is a "heavy" metal and has a higher cost. Therefore, aluminum was chosen as a light, cheap material with good thermal conductivity $(202 \mathrm{~W} / \mathrm{m} \cdot \mathrm{K})$. Moreover, making inserts from aluminum shavings is a rather simple process.

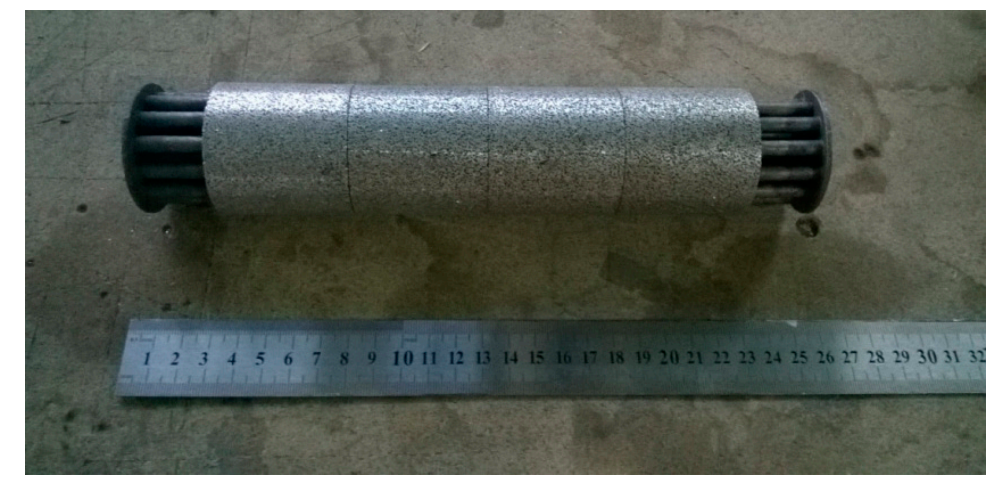

Figure 2. The inner part of the heat exchanger made of aluminum with porous filling.

For each of the two operation modes, the flow rate was changed by turning the valve, and the change in water temperature was recorded. Measurements were carried out for each of the four heat exchangers separately. Five values of water flow rates were considered, consumption rates were recorded. The numerical data of test protocols were used for calculations. Temperature changes for each flow rate were recorded 10-12 times. The experiments are carried out at a water temperature of $50{ }^{\circ} \mathrm{C}$ in the first operation mode and at $35^{\circ} \mathrm{C}$ in the second operation mode. During the experiments, various water temperatures were considered to verify the efficiency of the created test bench and to confirm the hypothesis about the effective cooling of coolant in heat exchangers with porous metals. By turning the valve, the coolant flow rate was adjusted at four-valve positions, which corresponded to flow rates in the range from 0.3 to $0.65 \mathrm{~m}^{3} / \mathrm{h}$ for the first operation mode, and in the range from 0.3 to $1.2 \mathrm{~m}^{3} / \mathrm{h}$ for the second operation mode.

\section{Results-Experimental Part}

The results of processing the obtained data are presented in Figure 3. Data recording at two modes of pump operation allows one to determine the intensity of heat transfer in the inserts. Here $Q$ is the thermal power of the heat exchanger of the considered design. 


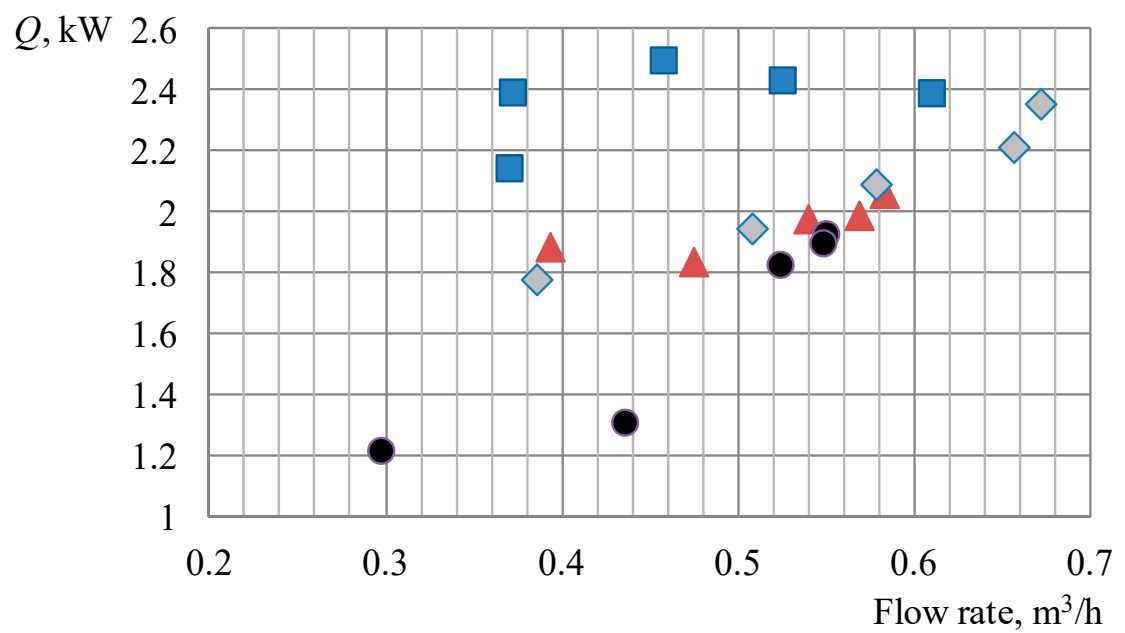

$\triangle \mathrm{HEp}=0.47 \diamond \mathrm{HEp}=0.49 \square \mathrm{HEp}=0.62 \bullet \mathrm{HE}$ without inserts

(a)

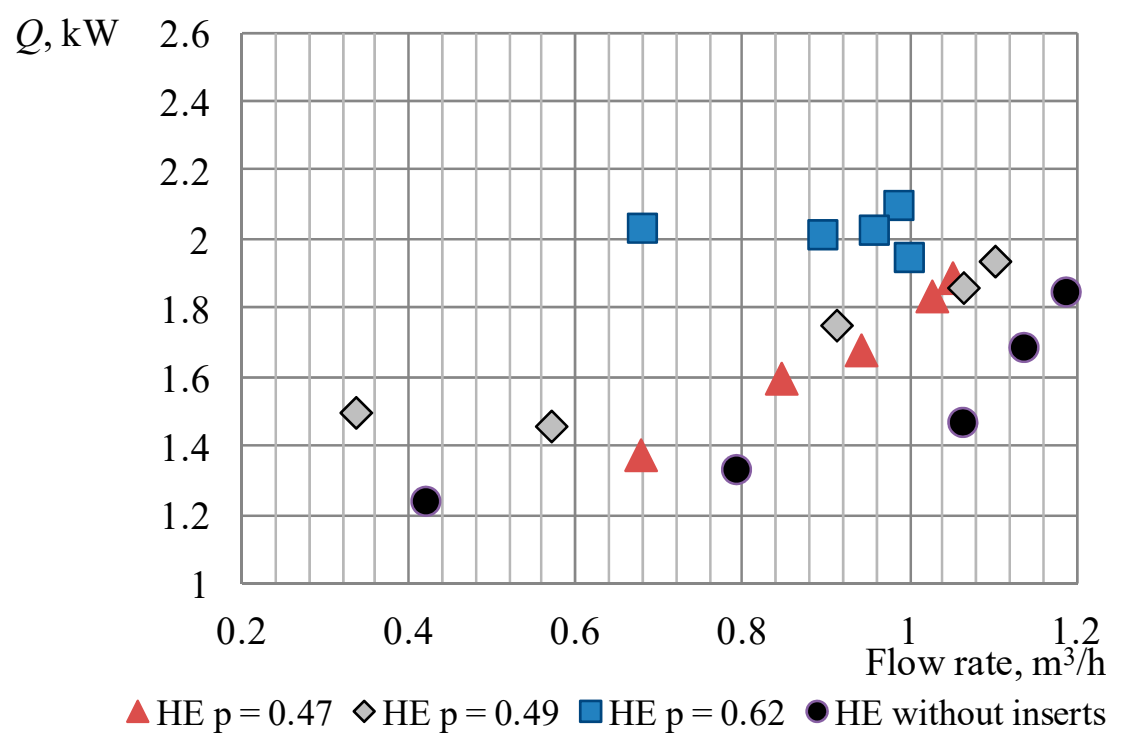

(b)

Figure 3. Thermal power of heat exchangers at different operation modes of water supply system: (a) the first operation mode; (b) the second operation mode.

Figure 3 shows that the higher amount of heat corresponds to the insert with the highest porosity. It can be noted that a conventional shell-and-tube heat exchanger (without porous inserts) was characterized by the least amount of heat.

Further, laboratory experiments were carried out to assess the intensity of the heat exchange of each heat exchanger. Before the main experiment, test runs were carried out for setting up the equipment. The experiment ran for $10 \mathrm{~min}$. The water heating temperature of $40-45^{\circ} \mathrm{C}$ was chosen, as during the operation of heat exchangers of the heat and gas supply system, the water temperature range was within $35-50{ }^{\circ} \mathrm{C}$. The device's readings were recorded every $2 \mathrm{~min}$. The interval for fixing the parameters was selected based on the test runs, in accordance with the most indicative temperature change after the considered period of time. The experiments were repeated many times. Based on the obtained data, graphs of temperature changes in time were constructed for the simultaneous operation of two circuits, Figure 4 . The subsequent plots were constructed for the flow of $1.1 \mathrm{~m}^{3} / \mathrm{h}$ for the opened valves. 


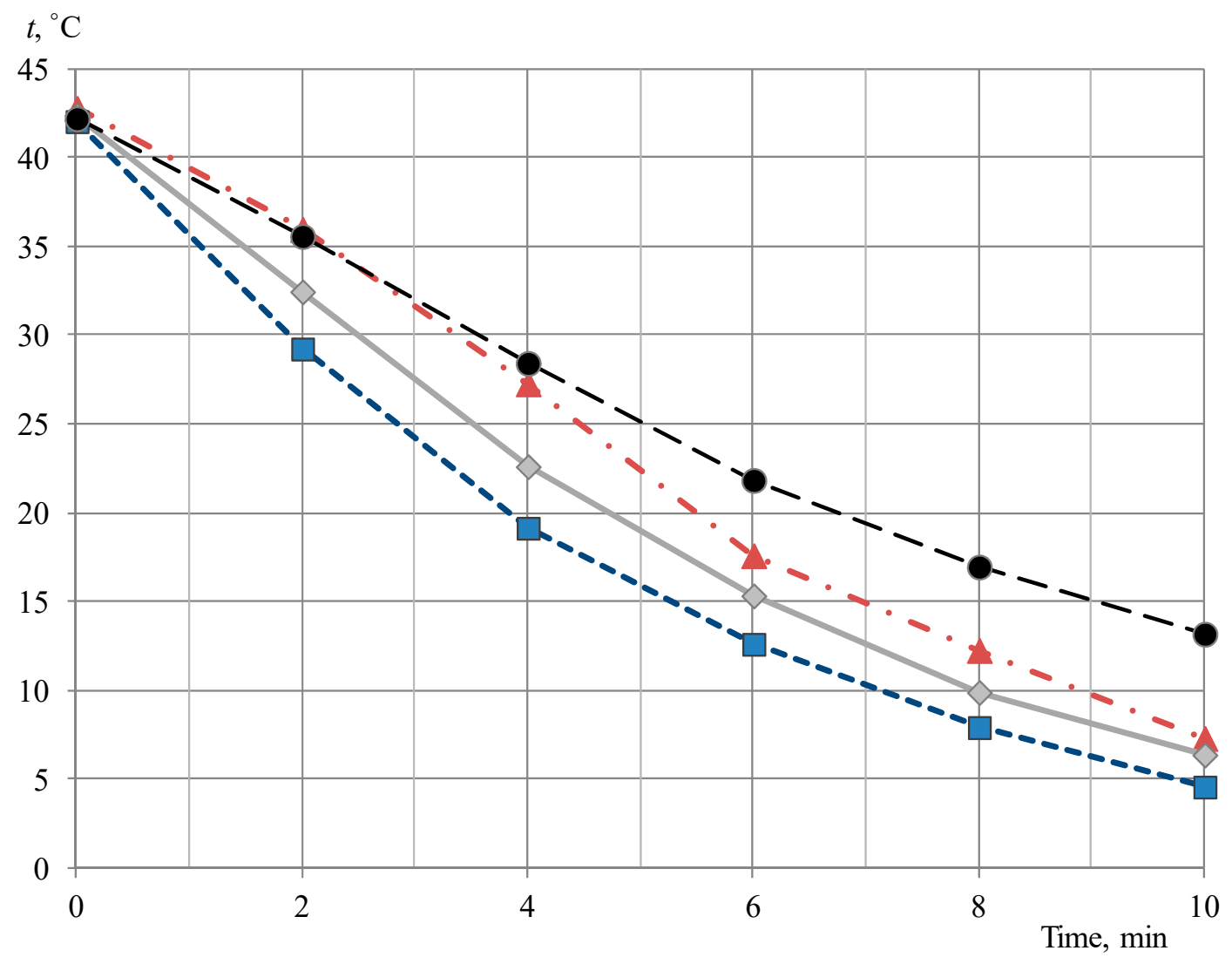

$\leadsto \cdot \mathrm{HE} \mathrm{p}=0.47 \precsim \mathrm{HEp}=0.49-\square-\mathrm{HEp}=0.62 \longrightarrow$ HE without inserts

Figure 4. Change in water temperature over time when cooled by freon.

Laboratory studies have shown that the thermal power of heat exchangers with porous filling was higher than that of HE without porous filling. After $10 \mathrm{~min}$ of operation of the test bench, the cooling efficiency of the heat exchanger with porosity $p=0.62$ was 1.5 times higher than that of HE without porous inserts. The cooling efficiency of HEs with porosities $p=0.49$ and $p=0.47$ was 1.2 times higher than that of the heat exchanger without porous inserts. Accordingly, the degree of water cooling was higher in heat exchangers with porous filling. The range of water temperature change from the initial $40-45^{\circ} \mathrm{C}$ depends on the porosity coefficient of the inserts. In this case, the plot of water temperature change of the heat exchanger 4 (without porous material) was higher.

An analysis of the accuracy of the measurements was also developed. In particular, the following results were obtained:

- Flow-rates: absolute measurement deviation $\pm 0.002 \mathrm{~m}^{3} / \mathrm{h}$, relative error $\pm 0.3 \%$

- Temperature: absolute measurement deviation $\pm 0.3{ }^{\circ} \mathrm{C}$, relative error $\pm 0.8 \%$

The relative errors of the measured values were quite limited, therefore, the obtained results could be considered reliable.

\section{Theoretical Study}

The theoretical study of heat transfer processes in porous media aimed to develop a simple calculation model for the considered porous material-based heat exchanger. Classical calculation methods for such heat exchangers are inapplicable since the heat exchange area inside the porous body is unknown. 
In an elementary volume, the change in heat flux $q$ due to heat transfer between a solid and a coolant flowing through the pores is expressed by [27], Figure 5:

$$
\mathrm{d} q_{\mathrm{x}}-\mathrm{d} q_{\mathrm{x}+\mathrm{dx}}=G_{\mathrm{c}} \times c_{\mathrm{pl}} \mathrm{d} t
$$

where $G_{\mathrm{c}}$ is the specific flow rate of cold coolant; $c_{\mathrm{pl}}$ is the heat capacity of cold coolant.

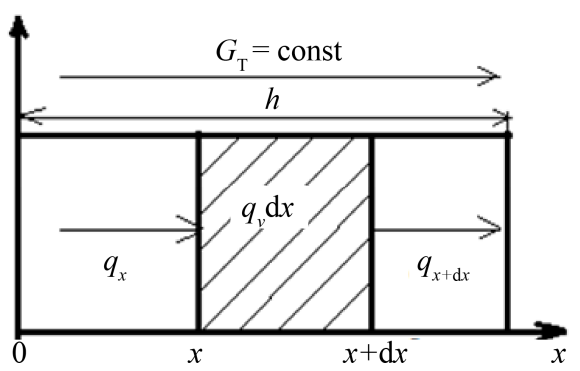

Figure 5. Porous cooling in an elementary volume.

Taking into account the fact that the temperatures of coolant and solid porous bodies are almost the same, then Equation (1) describes the process of heat exchange in a porous medium without pipes with water. If we take into account the presence of pipes with water in a heat exchanger, then Equation (1) can not be used since the temperature field becomes two-dimensional.

It is proposed to add to Equation (1) a term that takes into account the amount of heat released due to heat sources $q_{\mathrm{v}}$ distributed over the volume; the thermal resistance of the wall is neglected.

$$
\mathrm{d} q_{x}-\mathrm{d} q_{x+\mathrm{d} x}+q_{\mathrm{v}} \mathrm{d} x=G_{\mathrm{c}} \cdot \mathcal{c}_{\mathrm{pl}} \mathrm{d} t
$$

The density of heat flux in sections $x$ and $x+\mathrm{d} x$, taking into account the material's porosity is expressed as follows:

$$
\begin{gathered}
q_{x}=-\lambda_{\mathrm{c}} \frac{\mathrm{d} t}{\mathrm{~d} x}(1-p) \\
q_{x+\mathrm{d} x}=-\lambda_{\mathrm{c}} \frac{\mathrm{d}}{\mathrm{d} x}\left(t+\frac{\mathrm{d} t}{\mathrm{~d} x} \mathrm{~d} x\right)(1-p)
\end{gathered}
$$

where $\lambda_{c}$ is the coefficient of thermal conductivity of porous material (aluminum); $p$ is the porosity of filling, the ratio of the pore volume to the entire volume of material.

Heat flux density due to the heat source distributed over the volume is:

$$
q_{\mathrm{v}}=\frac{\alpha \cdot\left(t_{\mathrm{w}}-t\right) \cdot S_{\mathrm{p}}}{V_{\mathrm{a}}}
$$

where $\alpha$ is the coefficient of heat transfer from water to the copper wall; $t_{w}$ is the water temperature in the considered section $x ; S_{\mathrm{p}}$ is the total surface area of pipes; $V_{\mathrm{a}}$ is the volume of porous filling.

Substituting (3)-(5) into Equation (2) and performing a number of equivalent algebraic transformations, a second-order differential equation is obtained that describes the process of cooling a porous body with heat sources distributed in it:

$$
\frac{\mathrm{d}^{2} t}{\mathrm{~d} x^{2}}-\frac{G_{c} \cdot c_{\mathrm{p} l}}{\lambda_{c}(1-p)} \cdot \frac{\mathrm{d} t}{\mathrm{~d} x}+\frac{\alpha \cdot\left(t_{\mathrm{w}}-t\right) \cdot S_{\mathrm{p}}}{V_{\mathrm{a}} \lambda_{c}(1-p)}=0
$$

To simplify the solution of the resulting differential equation, the following notations are introduced:

$$
\xi_{c}=\frac{G_{c} \cdot c_{\mathrm{p} l}}{\lambda_{c}(1-p)},\left[\frac{1}{m}\right] ; A=\frac{\alpha \cdot\left(t_{\mathrm{w}}-t\right) \cdot S_{\mathrm{p}}}{V_{\mathrm{a}} \lambda_{c}(1-p)},\left[\frac{\mathrm{K}}{\mathrm{m}^{2}}\right] .
$$


The difference $t_{\mathrm{W}}-t$ is taken as the difference in the average temperatures of coolants. When considering the counterflow scheme and small heights of porous filling, the assumption is quite justified in view of a slight change in coolant temperature along the length of the porous filling.

The following restrictions are accepted as boundary conditions:

$$
0 \leq x \leq h, t(0)=t_{\mathrm{c} 1}, t(h)=t_{\mathrm{c} 2}
$$

where $h$ is the length of the porous insert; $t_{\mathrm{c} 1}, t_{\mathrm{c} 2}$ is the temperature of the coolant passing through the porous insert at the inlet and outlet, respectively.

As a result of solving the differential Equation (6) with the specified boundary conditions (8), the following equation is obtained:

$$
t=t_{\mathrm{c} 1}+\frac{A}{\xi_{\mathrm{c}}} x+\left(\mathrm{e}^{\xi_{\mathrm{c}} x}-1\right) \cdot \frac{t_{\mathrm{c} 2}-t_{\mathrm{c} 1}-\frac{A}{\xi_{\mathrm{c}}} \mathrm{h}}{\mathrm{e}^{\xi_{\mathrm{c}} h}-1}
$$

Equation (9) allows one to find the temperature of the coolant moving through the porous filling at any point $x$ for a known coolant temperature at the inlet.

The obtained temperature function (9) is further differentiated with respect to $x$ :

$$
\frac{\mathrm{d} t}{\mathrm{~d} x}=\frac{A}{\xi_{\mathrm{c}}} x+\frac{\left(t_{\mathrm{c} 2}-t_{\mathrm{c} 1}\right) \cdot \xi_{\mathrm{c}}-A \cdot h}{\mathrm{e}^{\xi_{\mathrm{c}} \mathrm{h}}-1} \cdot \mathrm{e}^{\xi_{\mathrm{c}} x}
$$

Substituting expression (10) into the heat flux density Equation (3), the formula for the heat flux is obtained for the case under consideration:

$$
q=-\lambda_{c} \cdot(1-p) \cdot\left(\frac{A}{\xi_{c}} x+\frac{\left(t_{\mathrm{c} 2}-t_{\mathrm{c} 1}\right) \cdot \xi_{c}-A \cdot h}{e^{\xi_{c} h}-1} e^{\xi_{c} x}\right)
$$

In Equation (11) the quantity $\lambda_{\mathrm{c}} \cdot(1-\epsilon)$ can be seen as an "apparent thermal conductivity" of the porous material, which depends on the nature of the material itself and on its porosity. The more conductive is the material, the higher is the porosity and the more intense is the heat transfer. Porous materials with high thermal conductivity determine a low thermal resistance and permit a better heat exchange. From this point of view, aluminum represents a good compromise in terms of thermal conductivity value and cost of the material.

Using expression (11), one can find the thermal power of the heat exchanger:

$$
\Delta Q=\left(q_{x=h}-q_{x=0}\right) \cdot S_{\mathrm{p}}
$$

The calculated thermal power is used to determine the temperature of the coolant moving through the pipes at the exit from the heat exchanger. Similarly, one can determine the coolant temperature at any point along the pipe length. To do this, we determine the temperature change:

$$
\Delta t=\frac{\Delta Q}{G_{\mathrm{w}} \cdot c_{\mathrm{pw}}}
$$

where $G_{\mathrm{w}}$ is the mass flow rate of water; $c_{\mathrm{pw}}$ is the water heat capacity. So at a given initial temperature:

$$
t_{2}=t_{1}-\Delta t
$$

Thus, having solved the compiled differential equation, a formula for finding the coolant temperature at any point of the porous body was obtained. In addition, a method was proposed for finding the temperature of the heat carrier, which is cooled in a heat exchanger with a porous filler. 


\section{Discussion}

Using the obtained Equation (9), the freon temperatures at the outlet from the considered porous heat exchangers with various $p$ were calculated. To check the accuracy of the calculation of the temperature of the coolant passing through the porous material, the freon temperature at the outlet of heat exchanger was used. The length of the porous insert was $h=0.2 \mathrm{~m}$.

The resulting dependences are shown in Figures 6 and 7. These data were compared with the experimental results carried out using the developed test bench.

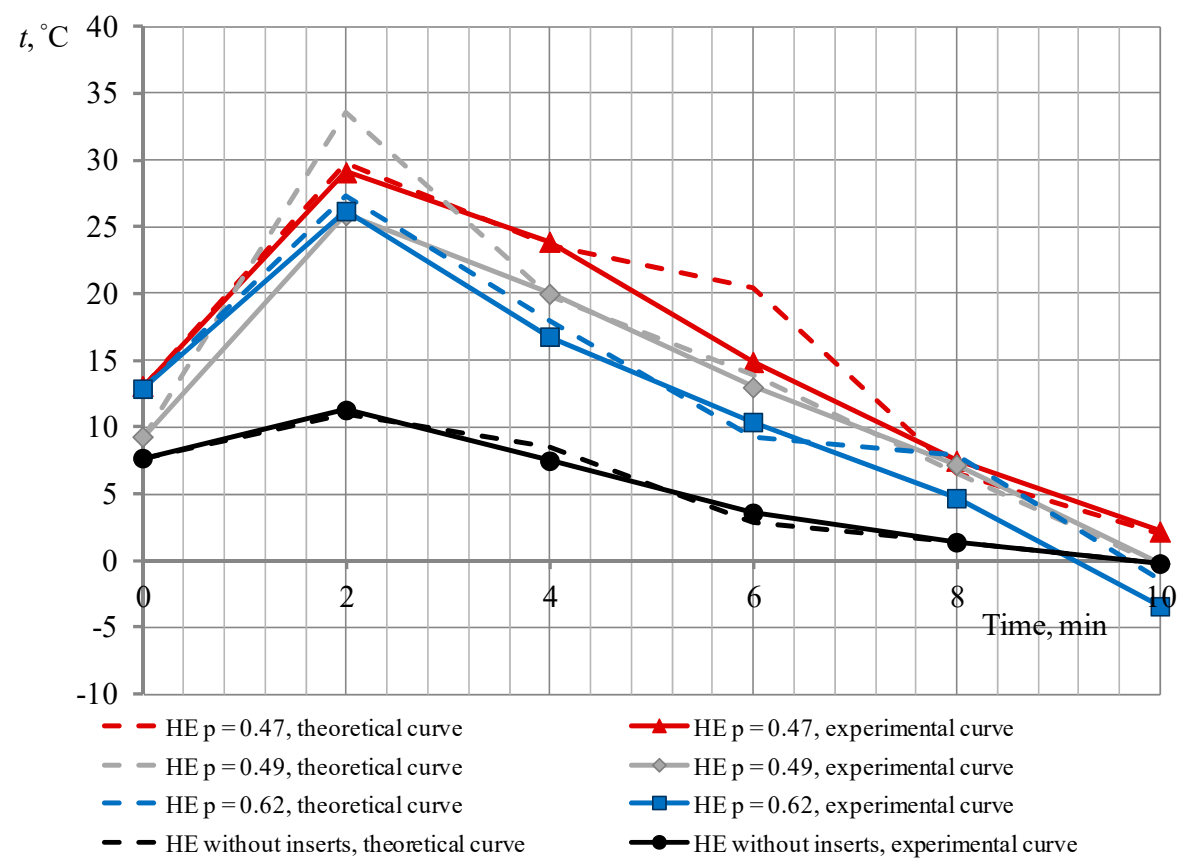

Figure 6. Calculated freon temperature at the outlet of the heat exchanger and their comparison with experimental data.

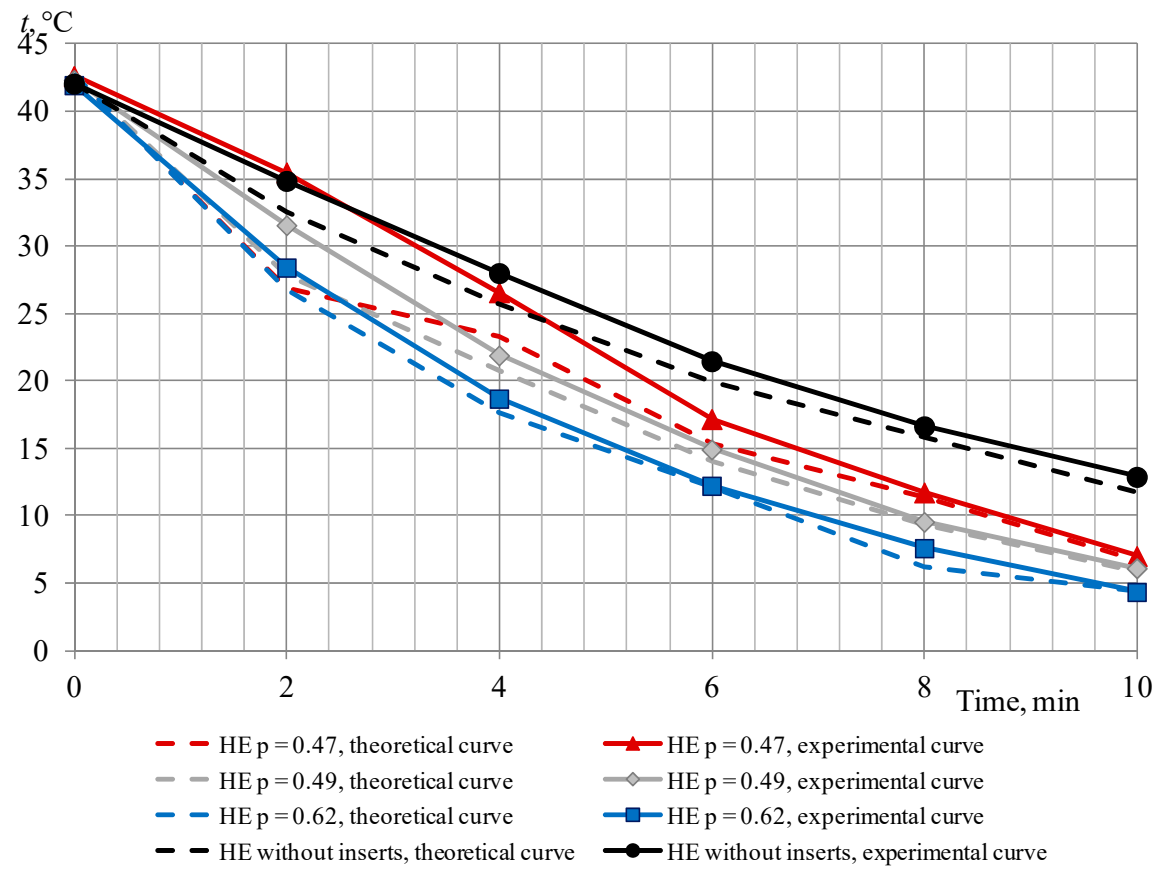

Figure 7. Calculated water temperature at the outlet of the heat exchanger and their comparison with experimental data. 
The theoretical curves in Figure 6, depicting the change in freon temperature at the outlet of the heat exchanger, for HEs with porous inserts were obtained as a result of calculations using Equation (9). The theoretical curve for a heat exchanger without porous inserts was obtained using the traditional method of thermal calculation for shell-and-tube heat exchangers. The increase in temperature during the first 2 min of operation (Figure 6) was explained by the stabilization of the operating mode from the moment the unit was turned on. During this time, the stationary operating mode was reached. The deviations of freon temperature at the outlet of the heat exchanger obtained from calculations are presented in Table 1.

Table 1. Average relative and absolute deviations between freon temperature at the HE outlet obtained from theoretical calculations and their empirical values.

\begin{tabular}{ccc}
\hline No. of Heat Exchanger & Relative Mean Deviation, $\mathbf{\%}$ & Absolute Mean Deviation \\
\hline $1(p=0.47)$ & 12.4 & 1.3 \\
$2(p=0.62)$ & 6.1 & 0.4 \\
$3(p=0.49)$ & 17.3 & 1.5 \\
4 (without inserts) & 11.6 & 0.9 \\
\hline
\end{tabular}

In heat engineering literature, relative deviations in the range of $17-18 \%$ are taken as acceptable and satisfactory. Absolute deviations within $1.5^{\circ} \mathrm{C}$ are also acceptable.

The expression (11) was used to calculate theoretical heat flux density, and further Equations (12)-(14) were used to calculate water temperature at the outlet from the heat exchanger with porous inserts. These values were compared with empirical data, obtained as a result of laboratory research, as shown in Figure 7. In addition, Figure 7 shows the theoretical curve of water temperature variation at the outlet of the heat exchanger without porous inserts, obtained according to the traditional method for the shell-and-tube heat exchanger and compared with experimental results. The resulting deviations are presented in Table 2.

Table 2. Mean relative and absolute deviations of the outlet water temperature calculated theoretically and obtained empirically.

\begin{tabular}{ccc}
\hline No. of Heat Exchanger & Relative Mean Deviation, \% & Absolute Mean Deviation \\
\hline $1(p=0.47)$ & 10.8 & 1.2 \\
$2(p=0.62)$ & 5.6 & 0.7 \\
$3(p=0.49)$ & 6.1 & 0.9 \\
4 (without inserts) & 7.3 & 1.1 \\
\hline
\end{tabular}

In accordance with the acceptable deviations given in the heat engineering literature, the obtained results were good. To further improve the model accuracy, the degree of material adherence to the walls of the heat exchanger should be taken into account.

The calculation results and their analysis in general, allows us to say that, given the initial temperature data at the inlet to a heat exchanger with porous material, the obtained model (9) and its derivative (11), allow us to determine the coolant temperature at the outlet of HE. In addition, the obtained formulas can be transformed to calculate heat exchangers of the considered type but having different geometric parameters. And using the presented equations, it is also possible to find the temperatures of heat carriers in any section of the heat exchanger.

Detailed economic calculations have not yet been carried out, but the design simplicity and the operation efficiency of heat exchangers with porous inserts, in comparison with that of devices using flow turbulization and devices with feathered surfaces, make it possible to obtain a greater amount of heat and a higher heat transfer coefficient. In addition, such heat exchangers can be used in real heat supply systems of enterprises and in urban heat supply systems, from boiler houses and combined heat and power plants to consumer heat points. In modern heat supply systems, water-water heat 
exchangers are used, which can be easily replaced by heat exchangers with porous inserts. For such heat exchangers, a preliminary economic calculation was carried out, and a positive economic effect was obtained when replacing water-water devices with heat exchangers with porous inserts, despite the increase in manufacturing costs and the presence of additional hydraulic resistances.

\section{Conclusions}

1. As a result of the study, the efficiency of using porous metals in heat exchangers has been experimentally confirmed. The increased heat transfer capabilities can be ascribed to the increased apparent conductivity of the porous medium and to the augmented thermal exchange surface. Conversely, penalties on the pressure drop are expected.

2. A mathematical model has been compiled, which makes it possible to find the temperatures of coolants at the outlet of a shell-and-tube heat exchanger having inserts made of porous metal.

3. The resulting model also makes it possible to determine the temperature of coolants in any section of the heat exchanger. The correctness of the compiled model has been confirmed experimentally.

4. Consequently, the performed experimental and theoretical studies make it possible to create more efficient heat exchangers that can be used in heat and gas supply systems for industrial and residential buildings.

5. Future researches can be oriented to the estimation of entropy generation of the proposed device in order to obtain an optimal device, where the two opposite contributions of the augmentation of heat transfer and increase of the pressure losses are balanced.

Author Contributions: Conceptualization, N.R. and E.A.; methodology, N.R., E.A., I.A., S.I. and O.A.; formal analysis, E.A., I.A. and V.B.; investigation, N.R., I.A. and O.A.; data curation, E.A. and S.I.; writing-original draft preparation, N.R., E.A., V.B. and O.A.; supervision, N.R.; writing-review and editing, A.F. All authors have read and agreed to the published version of the manuscript.

Funding: This research work was supported by the Academic Excellence Project 5-100 proposed by Peter the Great St. Petersburg Polytechnic University. Vincenzo Bianco acknowledges PRIN Project "Heat Transfer and Thermal Energy Storage Enhancement by Foams and Nanoparticles" (MIUR, grant. n. PRIN-2017F7KZWS).

Conflicts of Interest: The authors declare no conflict of interest.

\section{Abbreviations}

p porosity of filling;

$Q \quad$ thermal power, $\mathrm{kW}$;

$q \quad$ heat flux;

$G_{\mathrm{C}} \quad$ specific flow rate of cold coolant;

$\mathrm{c}_{\mathrm{pl}} \quad$ heat capacity of cold coolant;

$q_{\mathrm{v}} \quad$ the amount of heat released due to heat sources;

$\lambda_{c} \quad$ coefficient of thermal conductivity of porous material;

$\alpha \quad$ coefficient of heat transfer from water to the copper wall;

$t_{\mathrm{w}} \quad$ water temperature in the considered section $x$;

$S_{\mathrm{p}} \quad$ the total surface area of pipes;

$V_{\mathrm{a}} \quad$ volume of porous filling;

$\mathrm{h}$ the length of porous insert;

$t_{\mathrm{c} 1}, t_{\mathrm{c} 2} \quad$ temperature of coolant passing through the porous insert at the inlet and outlet, respectively;

$G_{\mathrm{W}} \quad$ mass flow rate of water;

$c_{\mathrm{pw}} \quad$ water heat capacity. 


\section{References}

1. Peng, X.; Li, D.; Li, J.; Jiang, S.; Gao, Q. Improvement of flow distribution by new inlet header configuration with splitter plates for plate-fin heat exchanger. Energies 2020, 13, 1323. [CrossRef]

2. Lee, H.J.; Ryu, J.; Lee, S.H. Influence of perforated fin on flow characteristics and thermal performance in spiral finned-tube heat exchanger. Energies 2019, 12, 556. [CrossRef]

3. Chai, L.; Tsamos, K.M.; Tassou, S.A. Modelling and evaluation of the thermohydraulic performance of finned-tube supercritical carbon dioxide gas coolers. Energies 2020, 13, 1031. [CrossRef]

4. Wajs, J.; Bajor, M.; Mikielewicz, D. Thermal-hydraulic studies on the shell-and-tube heat exchanger with minijets. Energies 2019, 12, 3276. [CrossRef]

5. Shafagh, I.; Rees, S.; Mardaras, I.U.; Janó, M.C.; Carbayo, M.P. A model of a diaphragm wall ground heat exchanger. Energies 2020, 13, 300. [CrossRef]

6. Jing, H.; Quan, Z.; Zhao, Y.; Wang, L.; Ren, R.; Liu, Z. Thermal performance and energy saving analysis of indoor air-water heat exchanger based on micro heat pipe array for data center. Energies 2020, 13, 393. [CrossRef]

7. Rashidi, S.; Kashefi, M.H.; Kim, K.C.; Samimi-Abianeh, O. Potentials of porous materials for energy management in heat exchangers-A comprehensive review. Appl. Energy 2019, 243, 206-232. [CrossRef]

8. Sarkar, M.; Velusamy, K.; Munshi, P.; Singh, O.P. Analysis of flow and heat transfer through a partially blocked fuel subassembly of fast breeder reactor. Prog. Nucl. Energy 2020, 118, 103142. [CrossRef]

9. Lu, H.; Yang, L.; Wu, Z.; Xu, S. Numerical and experimental study on convective heat transfer characteristics in foam materials. Energies 2020, 13, 348. [CrossRef]

10. Tan, W.; Saw, L.; Thiam, H.; Xuan, J.; Cai, Z.; Yew, M. Overview of porous media/metal foam application in fuel cells and solar power systems. Renew. Sustain. Energy Rev. 2018, 96, 181-197. [CrossRef]

11. Anirudh, K.; Dhinakaran, S. Performance improvement of a flat-plate solar collector by inserting intermittent porous blocks. Renew. Energy 2020, 145, 428-441. [CrossRef]

12. Robone, A.; Kuruneru, S.; Islam, M.; Saha, S. A macroscopic particle modelling approach for non-isothermal solid-gas and solid-liquid flows through porous media. Appl. Therm. Eng. 2019, 162, 162. [CrossRef]

13. Soto, C.; García-Rosales, C.; Echeberria, J.; Martínez-Esnaola, J.M.; Hernández, T.; Malo, M.; Platacis, E.; Muktepavela, F. SiC-based sandwich material for Flow Channel Inserts in DCLL blankets: Manufacturing, characterization, corrosion tests. Fusion Eng. Des. 2017, 124, 958-963. [CrossRef]

14. Buonomo, B.; Celik, H.; Ercole, D.; Manca, O.; Mobedi, M. Numerical study on latent thermal energy storage systems with aluminum foam in local thermal equilibrium. Appl. Therm. Eng. 2019, 159, 113980. [CrossRef]

15. Vikulin, A.V.; Yaroslavtsev, N.L.; Zemlyanaya, V.A. Investigation into Transpiration Cooling of Blades in High-Temperature Gas Turbines. Therm. Eng. 2019, 66, 397-401. [CrossRef]

16. Yang, X.; Yu, J.; Guo, Z.; Jin, L.; He, Y.L. Role of porous metal foam on the heat transfer enhancement for a thermal energy storage tube. Appl. Energy 2019, 239, 142-156. [CrossRef]

17. Akinshilo, A.T. Mixed convective heat transfer analysis of MHD fluid flowing through an electrically conducting and non-conducting walls of a vertical micro-channel considering radiation effect. Appl. Therm. Eng. 2019, 156, 506-513. [CrossRef]

18. Korsun, A.S.; Merinov, I.G.; Kharitonov, V.S.; Bayaskhalanov, M.V.; Chudanov, V.V.; Aksenova, A.E.; Pervichko, V.A. Numerical Simulation of Thermal-Hydraulic Processes in Liquid-Metal Cooled Fuel Assemblies in the Anisotropic Porous Body Approximation. Therm. Eng. 2019, 66, 225-234. [CrossRef]

19. Lu, X.; Zhao, Y. Effect of flow regime on convective heat transfer in porous copper manufactured by lost carbonate sintering. Int. J. Heat Fluid Flow 2019, 80, 108482. [CrossRef]

20. Kouidri, A.; Madani, B. Experimental hydrodynamic study of flow through metallic foams: Flow regime transitions and surface roughness influence. Mech. Mater. 2016, 99, 79-87. [CrossRef]

21. Hamadouche, A.; Nebbali, R.; Benahmed, H.; Kouidri, A.; Bousri, A. Experimental investigation of convective heat transfer in an open-cell aluminum foams. Exp. Therm. Fluid Sci. 2016, 71, 86-94. [CrossRef]

22. Buonomo, B.; Di Pasqua, A.; Ercole, D.; Manca, O. Numerical investigation on a Heat Exchanger in Aluminum Foam. Energy Procedia 2018, 148, 782-789. [CrossRef]

23. Hamadouche, A.; Azzi, A.; Abboudi, S.; Nebbali, R. Enhancement of heat exchanger thermal hydraulic performance using aluminum foam. Exp. Therm. Fluid Sci. 2018, 92, 1-12. [CrossRef] 
24. Qu, J.; Sun, Q.; Wang, H.; Zhang, D.; Yuan, J. Performance characteristics of flat-plate oscillating heat pipe with porous metal-foam wicks. Int. J. Heat Mass Transf. 2019, 137, 20-30. [CrossRef]

25. Davletbaev, V.; Rydalina, N.; Antonova, E. Experimental investigation of the heat exchange intensity. MATEC Web Conf. 2018, 245, 07002. [CrossRef]

26. Aksenov, B.; Rydalina, N.; Antonova, E. Porous Materials in Heat Exchangers Used in Heating. IOP Conf. Ser. Earth Environ. Sci. 2020, 459, 459. [CrossRef]

27. Stepanov, O.; Aksenov, B.; Rydalina, N.; Antonova, E. Heat-exchange units with porous inserts. E3S Web Conf. 2019, 140, 05006. [CrossRef]

Publisher's Note: MDPI stays neutral with regard to jurisdictional claims in published maps and institutional affiliations.

(C) 2020 by the authors. Licensee MDPI, Basel, Switzerland. This article is an open access article distributed under the terms and conditions of the Creative Commons Attribution (CC BY) license (http://creativecommons.org/licenses/by/4.0/). 